\title{
Chicken CCDC152 shares an NFYB-regulated bidirectional promoter with a growth hormone receptor antisense transcript and inhibits cells proliferation and migration
}

\author{
Shudai Lin ${ }^{1}$, Wei Luo ${ }^{1}$, Mingya Jiang ${ }^{1}$, Wen Luo ${ }^{1}$, Bahareldin Ali Abdalla ${ }^{1}$, Qinghua \\ $\mathrm{Nie}^{1}$, Li Zhang ${ }^{2}$ and Xiquan Zhang ${ }^{1}$ \\ ${ }^{1}$ Guangdong Provincial Key Lab of Agro-Animal Genomics and Molecular Breeding and Key Lab of Chicken Genetics, Breeding \\ and Reproduction, Ministry of Agriculture, College of Animal Science of South China Agricultural University, Guangzhou \\ 510642, P.R. China \\ ${ }^{2}$ Agricultural College, Guangdong Ocean University, Zhanjiang 524088, P.R. China \\ Correspondence to: Xiquan Zhang, email: xqzhang@scau.edu.cn \\ Li Zhang, email: zhangli761101@163.com
}

Keywords: bidirectional promoter, GHR antisense transcript, coiled-coil domain containing 152, NFYB, cell cycle

Received: December 15, $2016 \quad$ Accepted: September 04, $2017 \quad$ Published: September 20, 2017

Copyright: Lin et al. This is an open-access article distributed under the terms of the Creative Commons Attribution License 3.0 (CC BY 3.0 ), which permits unrestricted use, distribution, and reproduction in any medium, provided the original author and source are credited.

\section{ABSTRACT}

The chicken coiled-coil domain-containing protein 152 (CCDC152) recently has been identified as a novel one implicated in cell cycle regulation, cellular proliferation and migration by us. Here we demonstrate that CCDC152 is oriented in a head-tohead configuration with the antisense transcript of growth hormone receptor (GHR) gene. Through serial luciferase reporter assays, we firstly identified a minimal 102 bp intergenic region as a core bidirectional promoter to drive basal transcription in divergent orientations. And site mutation and transient transfected assays showed that nuclear transcription factor $Y$ subunit beta (NFYB) could bind to the CCAAT box and directly transactivate this bidirectional promoter. SiRNA-mediated NFYB depletion could significantly down-regulate the expression of both GHR-AS-I6 and CCDC152. Additionally, the expression of GHR-AS-I6 was significantly up-regulated after CCDC152 overexpression. Overexpression of CCDC152 remarkably reduced cell proliferation and migration through JAK2/STAT signaling pathway. Thus, the GHRAS-I6-CCDC152 bidirectional transcription unit, as a novel direct target of NFYB, is possibly essential for the accelerated proliferation and motility of different cells.

\section{INTRODUCTION}

Most genes in prokaryotes are economically organized at a high density and arranged in operons, ensuring effective co-regulation of genes [1]. In contrast, in higher eukaryotes, genes are organized at low density and arranged individually, which facilitates flexible and precise regulation [2]. Surprisingly, the sequencing data of the human genome found that more than $10 \%$ of genes are shown in a divergent or "head-to-head"configuration with an intervening sequence of less than $1 \mathrm{~kb}$ [3-5]. Strikingly, transcription of such gene pairs is driven by unique, bidirectional promoters that initiate transcription in both directions and contain shared elements that regulate both genes [6,7].

Expression of gene pairs transcribed by a bidirectional promoter is likely to be correlated; the two genes always share a similar function and are regulated by the same transcription factor [8-11]. Increasing studies strongly demonstrated that these gene pairs play important roles in biological processes, such as DNA damage signaling pathway and the development of cells $[12,13]$, and even various diseases such as cancer $[6,14,15]$. In the human genome, no more than 20 of these gene pairs have been identified and characterized in details, including BRCA1-NBR2, Mrps12-Sarsm, and PRR11-SKA2 [13]. However, in the chicken genome, just two gene pairs have been reported in detail, including GPAT-AIRCR $[16,17]$ and Rap1-KARS [18]. Previously, we have identified a novel chicken gene product, growth hormone receptor $(G H R)$ antisense transcript intron 6 (GHR-AS-I6), a novel natural transcript initiating from the 3 ' flanking region and ending in intron 6 in the opposite strand of GHR gene, 
which is partially complimentary to GHR messenger RNA (mRNA) and recruits to the GHR promoter to regulate the expression level of GHR mRNA [19].

The coiled-coil domain-containing (CCDC) proteins exhibit different kinds of functions due to their highly versatile folding motif $[20,21]$. The coiled-coil motif is found in many proteins, such as skeletal and motor proteins, and is involved in molecular recognition systems and protein refolding [20-22]. It was also reported that CCDC proteins were involved in the process of gene transcription events, cell cycle regulation, apoptosis, and the invasion and metastasis of malignant tumor cells [23-30]. Notably, CCDC80 (also known as Equarin) is involved in chicken eye formation [31] and is strongly expressed in the notochord of zebrafish [32]. However, the functions of numerous $C C D C$ genes, such as $C C D C 152$, remain unclear.

Intriguingly, we noticed that the chicken $G H R-A S-I 6$ and $C C D C 152$ are closely located on chromosome $\mathrm{Z}$ in a head-to-head orientation, suggesting that both genes are coordinately regulated by a unique bidirectional promoter. Here, we propose that the transcription of both GHR-AS-I6 and CCDC152 were controlled by a bidirectional promoter, and $C C D C 152$ plays role in cell cycle progression and cell migration in vitro.

\section{RESULTS}

\section{The organization of GHR-AS-I6 and CCDC152 transcripts}

To determine whether chicken GHR-AS-I6 and $C C D C 152$ are bidirectional transcripts, we used $G H R$ $A S-I 6$ [19] and the downloaded CCDC152 sequence and employed the NCBI BLAST (http://blast.ncbi.nlm. nih.gov/Blast.cgi) to analyze the genomic organization. As shown in Figure 1A, GHR-AS-I6 and CCDC152 are matched to chromosome $\mathrm{Z}$ in a head-to-head orientation, with the transcripts separated by approximately $1000 \mathrm{bp}$. Notably, the intergenic region between GHR-AS-I6 and CCDC152 was 1180 bp (chrZ: 13571950 to 13573129), which was considered as an active promoter region (Figure 1A) by using network tools Promoterscan and Softberry for prediction. Taken together, the above results strongly suggest that chicken GHR-AS-I6 and CCDC152 are a classic head-to-head transcriptional gene pair probably driven by a unique bidirectional promoter.

\section{The transcription start sites of GHR-AS-I6 and CCDC152}

To see the transcription start sites of GHR-AS-I6 and $C C D C 152$ and to clarify the intergenic region, we first analyzed $C C D C 152$ using the online tools Jaspar and PROMO to predict the TATA box and transcriptional factor binding sites in the 1180 bp promoter region, respectively. We found that there was only one transcription start site (TSS) located at 13572834 for GHR-AS-I6 and 4 TSSs located at position $13572583,13572603,13572889$ and 13572916 for $C C D C 152$, indicating that there may be various $5^{\prime}$ un-translated regions for CCDC152 mRNA transcripts (Figure 1B).

To further verify the predicted results, we conducted 5'-RACE analysis using total RNAs from WRR chicken liver and leg muscle tissues. As shown in Supplementary Figure 1, different PCR products were amplified from WRR chicken liver and leg muscle tissues. Subsequent cloning and sequencing analysis of the 5'-RACE products revealed that a single major transcription start site for CCDC152 is present at position 13572916 in chicken liver tissue (Figure 1B).

Combining the predicted analysis and our 5'-RACE results, we assigned position 13572916 as the major TSS for $C C D C 152$, but we could not amplify the 5' end of $G H R-A S-I 6$. Hence, for further analysis, we designated the major transcription start site of $C C D C 152$ at position 13572916 as +1 .

\section{Identification of the GHR-AS-I6-CCDC152 bidirectional promoter region}

To investigate whether the intergenic region of $G H R-A S-I 6-C C D C 152$ acts as a bidirectional promoter, a series of luciferase reporter constructs were generated by inserting various intergenic fragments of the GHR-AS-I6$C C D C 152$ transcription pair in both orientations into the promoter-less pGL3-basic vector (Figure 2). The promoter activities were assessed following transient transfection of these reporters into LMH cells. As shown in Figure 2B, all deletion constructs of CCDC152 displayed significant promoter activities with different efficiencies. Compared with pGL3-basic vector, all deletion constructs of GHR$A S$-I6 showed higher but not-significant promoter activities.

Notably, a short segment of 504 bp (-996 bp to $-463 \mathrm{bp}$ ) was activated in both orientations in LMH cells, strongly suggesting that this genomic region displays strong constitutive bidirectional promoter activity that drives transcription of both GHR-AS-I6 and CCDC152. Additionally, strong enhancers for $C C D C 152$ were predicted to reside in the sequence between positions $-650 \mathrm{bp}$ and $-463 \mathrm{bp}$. Indeed, compared with GHR-ASI6-P1180 $(P<0.05)$, GHR-AS-I6-P874 and GHR-ASI6-P504 $(P<0.01)$, the $G H R-A S-I 6$ constructs P317, which exclude this fragment, displayed the highest activity in the $G H R-A S-I 6$ orientation. Strong silencers for $G H R-A S-I 6$ were predicted to reside in the sequence between positions -650 and -463 . Consistent with this prediction, we observed a sharp increase in the promoter activity of GHR-AS-I6-P317 compared with that of GHRAS-I6-P504. 
To further minimize the genomic region of the GHR-AS-I6-CCDC152 bidirectional promoter, additional luciferase reporter constructs containing the indicated 13571950 to 13572051 (102 bp) were generated and transiently transfected into LMH cells (Figure 3 ). The luciferase assay revealed that all the constructs including the shortest one, P102 (-996/-895), exhibited remarkable promoter activities, suggesting that a minimal (core) GHR-AS-I6-CCDC152 bidirectional promoter is present within the genomic region between -996 and -895 (Figure 3). These findings strongly suggested that $G H R$ $A S-I 6$ and CCDC152 transcripts are classic head-to-head transcriptional pair, and possibly driven by a bidirectional promoter.

A

Chromosome Z - NC . 006127.4
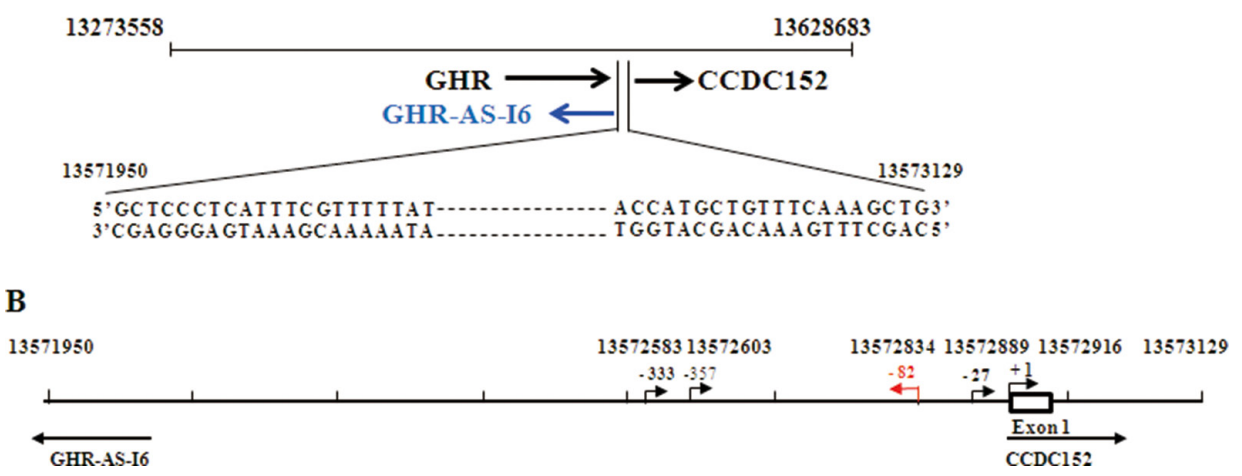

Figure 1: Genomic organization of the GHR-AS-I6 and CCDC152. (A) The location of the intervening region of GHR-AS-I6$C C D C 152$ in the chicken genome. (B) The potential transcript start sites of GHR-AS-I6-CCDC152 bidirectional promoter predicted by online software Fruitfly and PromoterScan. The $13572916(+1)$ site was verified by 5'-RACE.

A
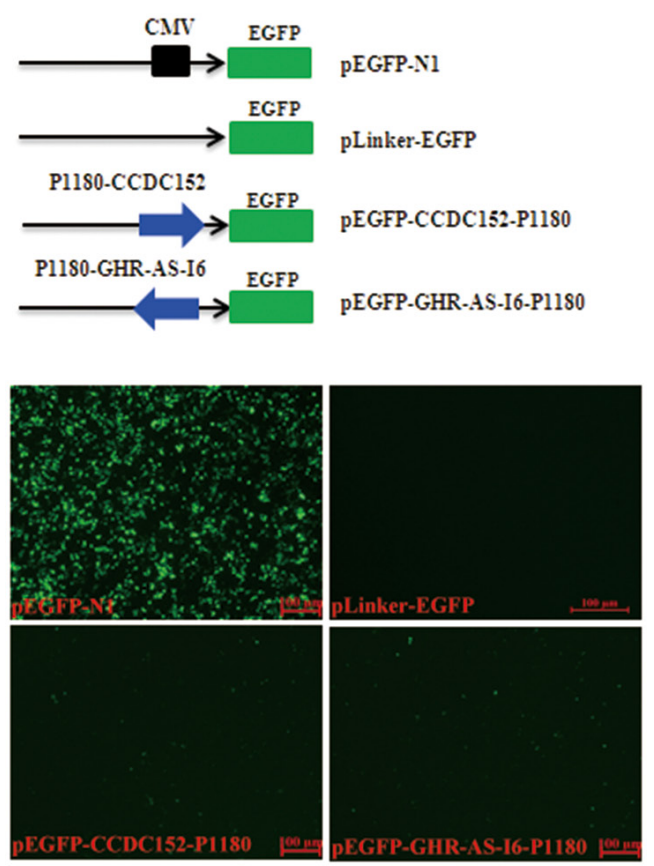

B

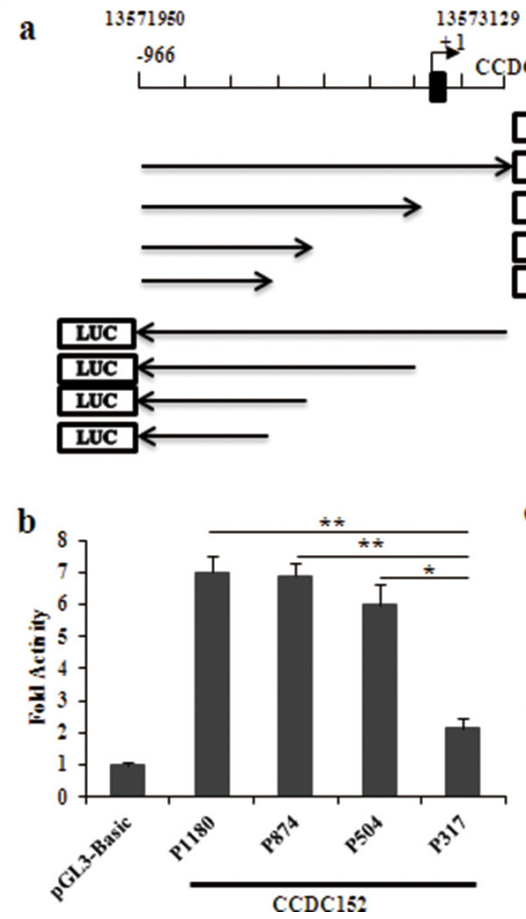

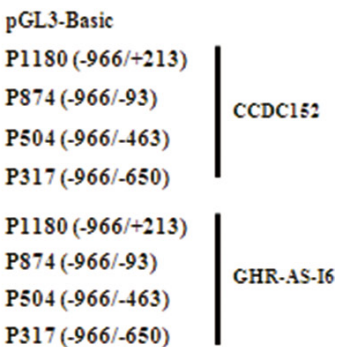

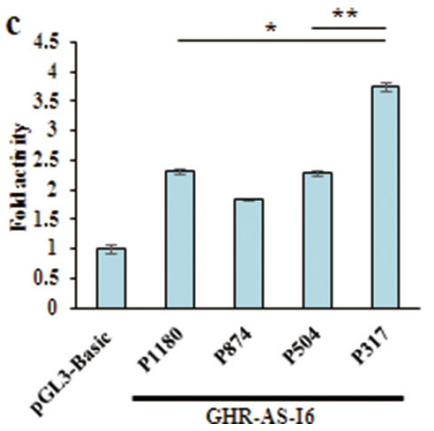

Figure 2: Identification of the proximal GHR-AS-I6-CCDC152 bidirectional promoter region. (A) The green fluorescent protein (GFP) detection of both CCDC152 and GHR-AS-I6 directional promoter region in LMH cells transfected with positive control pEGFP-N1, and negative control pLinker-EGFP (without CMV promoter) $(40 \times$ magnification). (B) The upper panel shows a schematic diagram of the luciferase reporter constructs containing the indicated genomic fragments of this GHR-AS-I6-CCDC152 pair. Positions relative to the major transcriptional initiation site of CCDC152 (+1) are indicated. LMH cells were transiently co-transfected, in triplicate, in 24-well culture plates with the indicated luciferase reporter constructs together with the Renilla luciferase reporter plasmid (pRL-TK). Firefly and Renilla luciferase activities were measured $48 \mathrm{~h}$ after transfection. Data are shown as fold induction compared with the activity of cells transfected with the empty promoter-less pGL3-basic luciferase reporter vector alone. The results are shown as the mean \pm S.E.M of triplicate experiments. Significance: *,* indicate $P<0.05$ and $P<0.01$, respectively. 


\section{The NFYB binding sites in the bidirectional promoter}

We used online tools Jaspar and PROMO to identify putative consensus binding sequences, predominantly the CCAAT box for NFYB, within the GHR-AS-I6-CCDC152 bidirectional promoter region (Figure $4 \mathrm{~A}$ and $4 \mathrm{C}$ ). To confirm whether the NFYB influences the transcriptional activity of this bidirectional promoter, we conducted site mutation constructs and transient transfection assays. For CCDC152, promoter mutated TATA box (Figure 4A and 4B, M2, M6) and CCAAT box (Figure 4A and 4B, M7) decreased sharply in activity, while the mutation in M5 and M8 sites resulted in a different increase in its promoter activity (Figure 4B). For $G H R-A S$-I6 promoter, mutations of TATA box and CCAAT box decreased promoter activity in the excluded $\mathrm{M}^{\prime}$ site, especially mutations in M4, M6, M7 and M8 sites (Figure 4C and 4D). Considering Figure $3 \mathrm{C}$, the CCAAT box plays an important role in maintaining bidirectional promoter activity. Taken together, the TATA box in M6 site and the CCAAT box in M7 site play very important roles in activating the bidirectional promoter. Thus, we next focused on M7, the NFYB binding site, and verified its role in the transcriptional regulation of the GHR-AS-I6-CCDC152 bidirectional promoter.

\section{NFYB combines with NFYC to transactivate transcription of the bidirectional promoter}

Numerous studies have demonstrated that the transcription factor NFYB plays a fundamental role in the transcriptional regulation of cell cycle genes, particularly G2/M genes [33-35]. From the ChIP assay (Figure 5A), we confirmed that the NFYB/C could bind to the CCAAT box. And to give insight into whether NFYB affects the expression of GHR-AS-I6 and CCDC152, LMH cells were transiently transfected with pc3.1-NFYB overexpression or interference with $N F Y B$ (si-NFYB) (Figure 5B), or respective controls. When $N F Y B$ overexpressed, the expression levels of both $G H R-A S-I 6$ and $C C D C 152$ were significantly increased (Figure 5C).

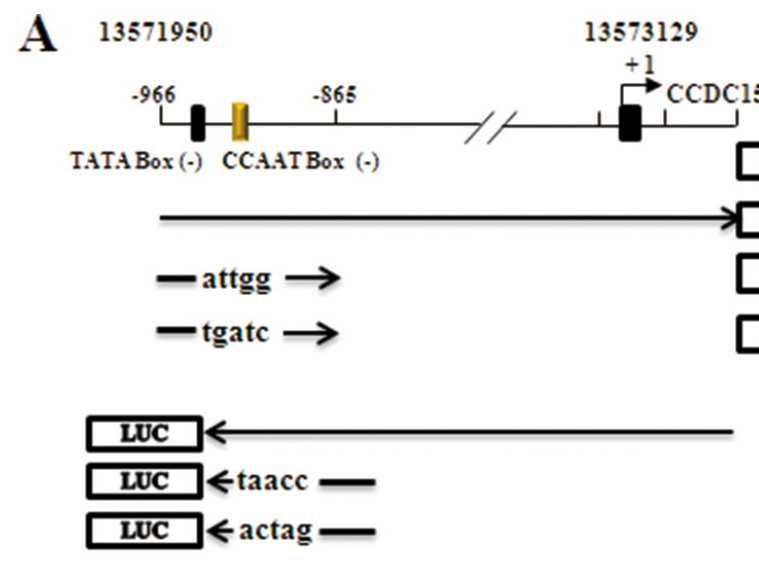

\begin{tabular}{l|l} 
pGL3-Basic & \\
P1180 (-966/+213) & CCDC152 \\
P102 (CCDC152)-wt $(-966 /-865)$ & \\
P102 (CCDC152)-mut $(-966 /-865)$ &
\end{tabular}

P1180 (-966/+213)

P102 (GHR-AS-I6)-wt (-966/-865)

P102 (GHR-AS-I6)-mut (-966/-865)

GHR-AS-I6
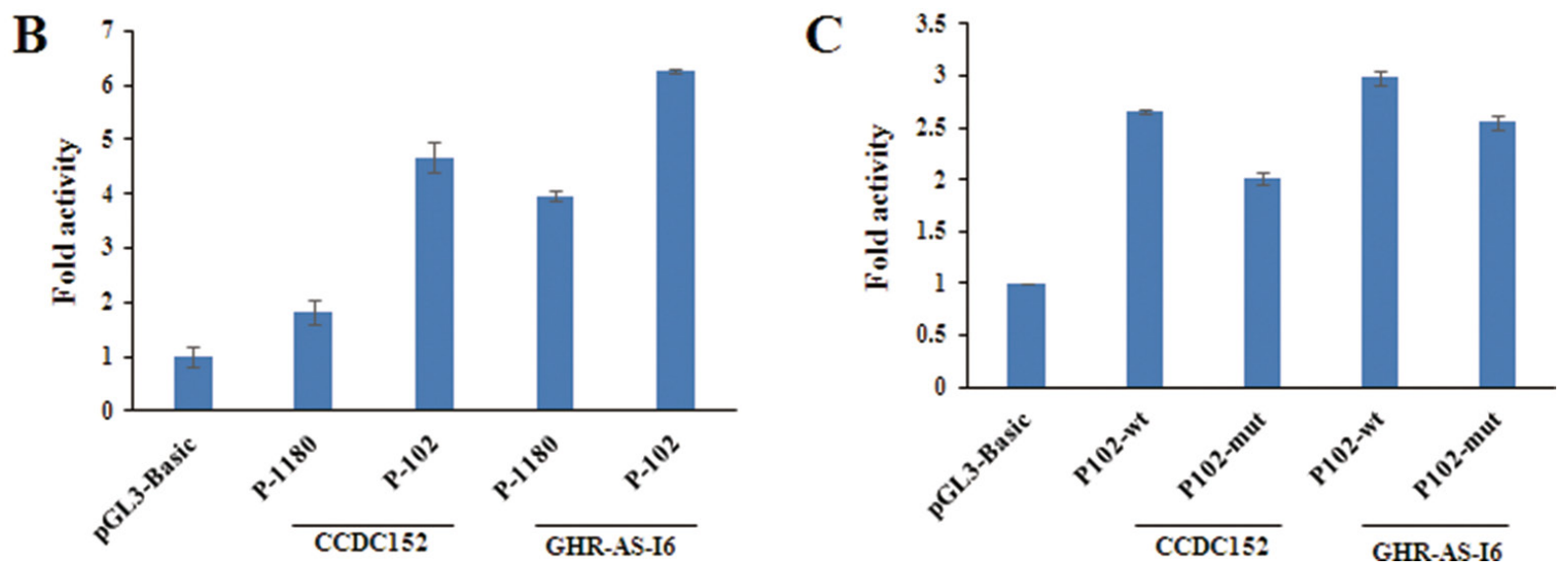

Figure 3: Identification of the core GHR-AS-I6-CCDC152 bidirectional promoter region. (A) The constructs of wild type (wt) and mutation core promoter region (mut) from -966 to -865 (P102). The position relative to the major transcriptional initiation site of CCDC152 (+1) are indicated. $(\mathbf{B}, \mathbf{C})$ Results of the reporter assay: LMH cells were transiently co-transfected with the indicated luciferase reporter constructs along with pRL-TK. Firefly and Renilla lusiferase activities were measured and analyzed $48 \mathrm{~h}$ after transfection, as described in Figure 2. The results are shown as the mean \pm S.E.M of triplicate experiments. Significance: $*, * *$ indicate $P<0.05$ and $P<$ 0.01 , respectively. 
Next, to understand whether NFYB activates transcription of $G H R-A S-I 6-C C D C 152$ bidirectional promoter, LMH cells were co-transfected with an NFYB expression vector (pc3.1-NFYB) and/or a series of $G H R-A S-I 6-C C D C 152$ luciferase reporters (Figure 3A, Figure 5B and 5D). The luciferase reporter assay revealed that overexpression of $N F Y B$ caused a significant increase in luciferase activities of the shortest constructs GHR-AS-I6-P102 and CCDC152-P102, strongly suggesting that NFYB activates the GHR-AS-I6-CCDC152 bidirectional promoter in both orientations (Figure 5D). Conversely, knockdown of $N F Y B$ caused a significant decrease in the luciferase activity of the shortest constructs GHRAS-I6-P102 and CCDC152-P102 (Figure 5F and 5G).

Furthermore, we performed qRT-PCR and Western blot to detect whether NFYB was involved in regulating the expression of CCDC152 protein and how it works. The results showed that the expression levels of CCDC152 and NFYC were increased by the overexpression of NFYB (Figure 5E, 5I and 5J); conversely, their expression

\section{A CCDC152 promoter}

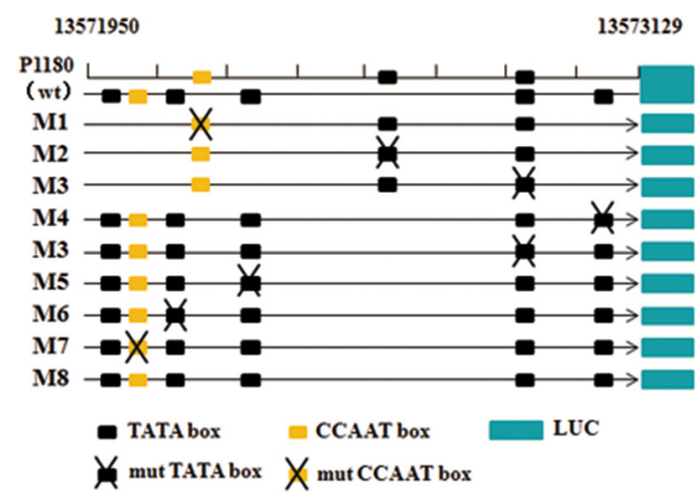

\section{B CCDC152 promoter}

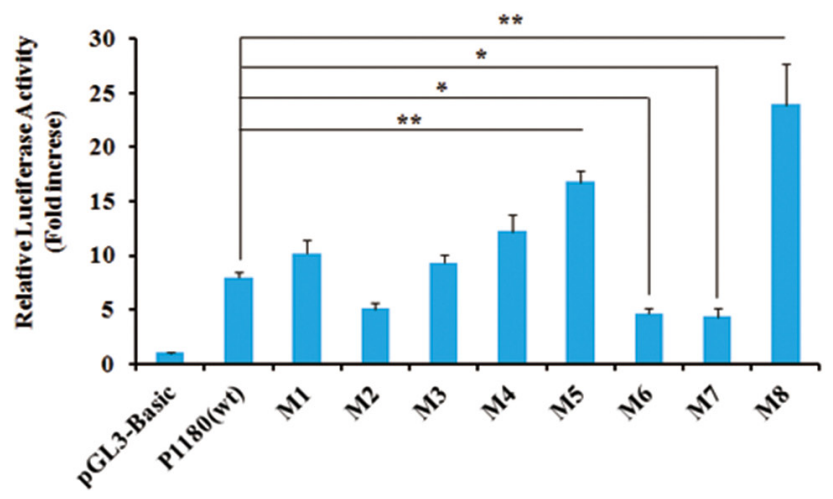

decreased with knockdown of $N F Y B$ (Figure 5H, 5I and 5J). Taken together, NFYB could react with NFYC but not NFYA to transactivate the bidirectional promoter to launch $G H R-A S-I 6$ and $C C D C 152$ activity.

\section{CCDC152 regulates the transcription of GHR- AS-I6 and itself}

Here, we asked whether the CCDC152 could influence the expression of GHR-AS-I6 and CCDC152. It has been reported that $\mathrm{CCDC}$ proteins can play various roles due to their highly versatile folding motif [20]. CCDC genes take part in the processes of gene transcription, apoptosis and the cell cycle and even in the invasion and metastasis of malignant tumor cells $[14,29]$. As expected, from the result of overexpression of $C C D C 152$ in LMH cells and qRT-PCR, we found that the expression of $G H R-A S-I 6$ is significantly increased (Figure 6A). However, the promoter activities in both orientations are decreased (Figure 6B). When interfering with $C C D C 152$, the expression of $G H R-A S-I 6$ was

\section{GHR-AS-16 promoter}

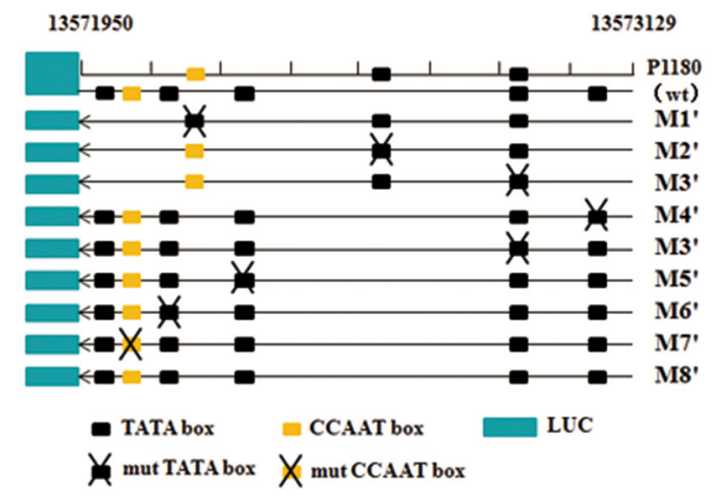

D GHR-AS-16 promoter

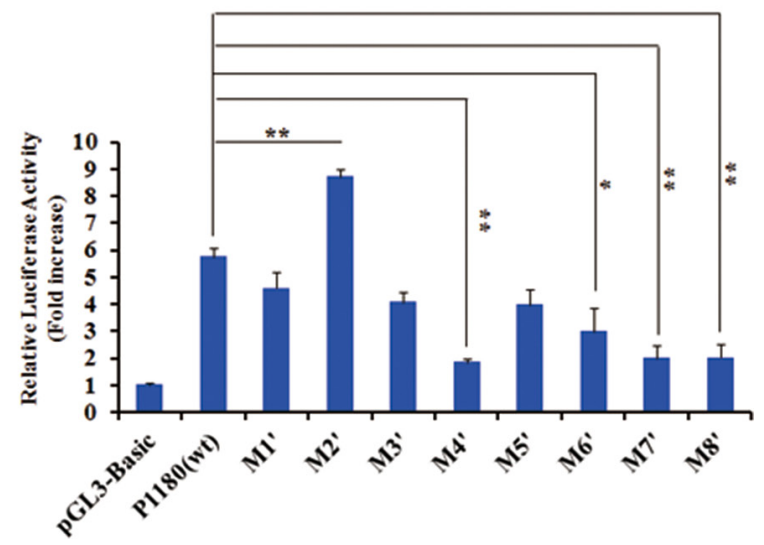

Figure 4: Identification of the NFYB binding sites of the bidirectional promoter. The potential TATA box and CCAAT box in the bidirectional promoter and the schematic structure of a serial mutation constructs of TATA box and CCAAT box (A, C). The promoter activity of the normal and mutation bidirectional promoter in LMH cells (B, D). Significance: ${ }^{*}, * *$ indicate $P<0.05$ and $P<$ 0.01 , respectively. 
significantly decreased (Figure 6C), while promoter activities in both orientations are increased (Figure 6D).

To investigate how the CCDC152 affect the expression of GHR-AS-I6 and CCDC152, we first performed qRT-PCR assay and Western blot of NFYB and NFYC. The result showed that the expression of both $N F Y B$ and $N F Y C$ didn't change with changing $C C D C 152$ expression (Figure 6E), but the NFYB protein was significantly increased by overexpressing $C C D C 152$ (Figure 6F). In addition, we also analyzed the expression of genes in JAK/STAT pathway. The expressions of $J A K 2$, STAT1-3 and STAT5B were increased with knockdown of CCDC152, and the STAT3, STAT4 and STAT5B was decreased with significance by knockdown of $C C D C 152$ (Figure 6G). These observations support the hypothesis that CCDC152 functions as a transcriptional inhibitor of $G H R$ $A S-I 6-C C D C 152$ bidirectional promoter in LMH cells.

\section{Silencing of CCDC152 increases cell proliferation}

We tested the effect of $C C D C 152$ on cell cycle progression and distribution using flow cytometry. As shown in Figure 7A and 7B, compared with control, overexpression of $C C D C 152$ in $\mathrm{LMH}$ cells promoted a significant arrest in the cell cycle at the $\mathrm{G} 0 / \mathrm{G} 1$ phase and reduced the number of proliferating cells. Knockdown of CCDC152 in LMH cells promoted a significant shift of the cell cycle to the G2 phase from $\mathrm{G} 1$ and $\mathrm{S}$ phase and increased the number of proliferating cells (Figure 7C, 7D and 7E). Considering these findings with Figure $6 \mathrm{G}$ together, we argued that a high level of $C C D C 152$ expression could inhibit cell proliferation and a low level of CCDC152 expression would promote cell proliferation through JAK2/STAT signaling pathway.

\section{A ChIP-PCR and qPCR}

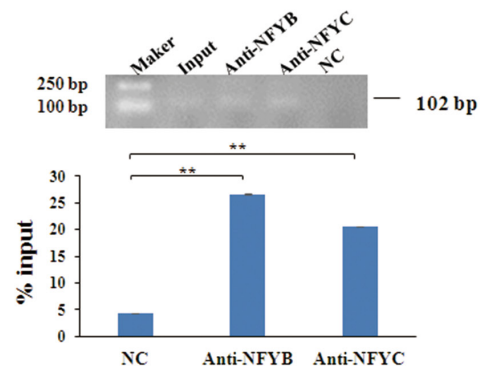

B Constructs of pc3.1-EGFP and pc3.1-NFYB

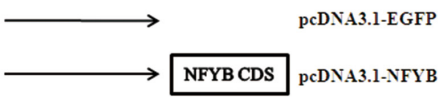

E

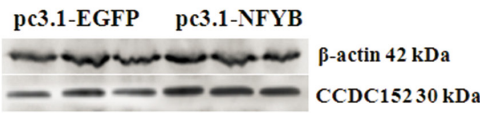

C

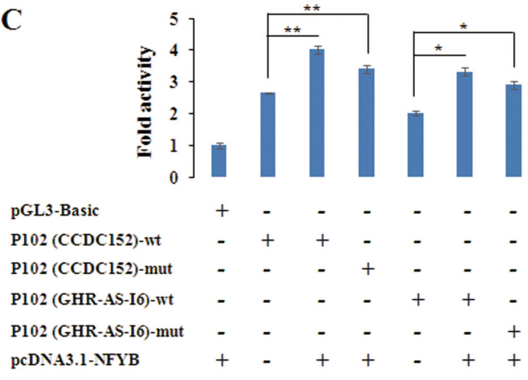

$\mathbf{F}$

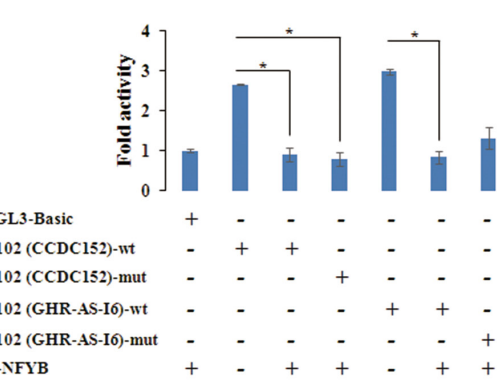

D

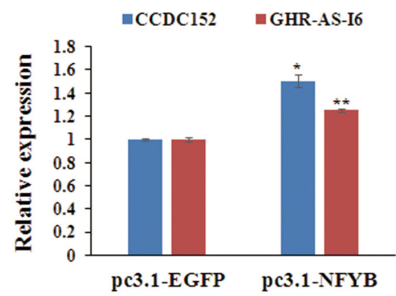

G

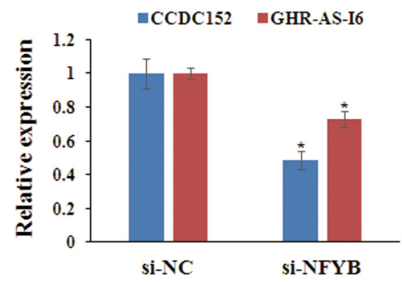

H

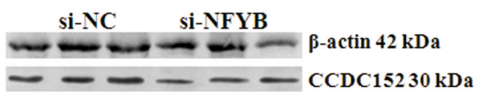

I

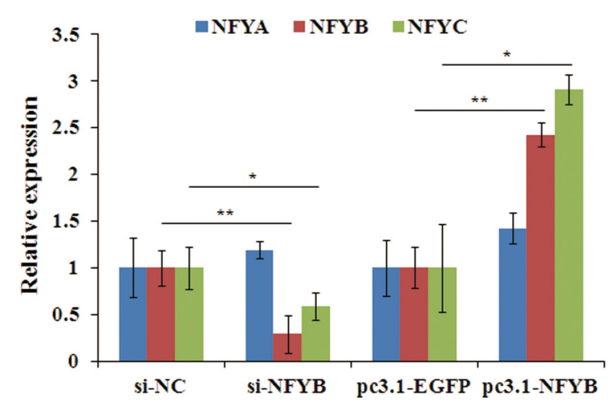

$\mathbf{J}$

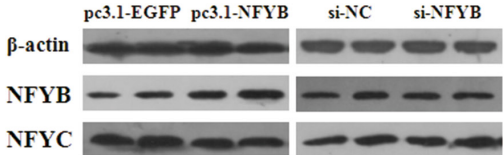

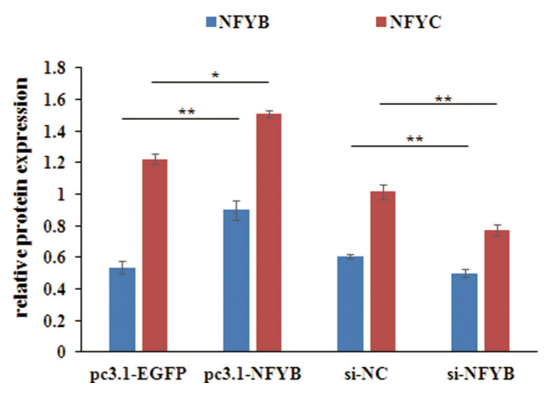

Figure 5: NFYB directly transactivates the transcription of both GHR-AS-I6 and CCDC152. (A) ChIP assay was used to detect the binding of NFYB and NFYC proteins to CCAAT box of the bidirectional promoter. (B) The constructs of overexpression of $N F Y B$ (pc3.1-NFYB) and control cells transfected with the empty vector (pc3.1-EGFP). Relative expression levels of CCDC152, GHR-AS-I6 and NFYA/B/C are shown after overexpressing $N F Y B$ and interfering $N F Y B(\mathbf{C}, \mathbf{F}, \mathbf{I})$. The bidirectional promoter activity has been changed after inducing $N F Y B(\mathbf{D})$ and interfering $N F Y B(\mathbf{G})$. The protein level of CCDC152 and NFYB were up-regulated and down-regulated after overexpressing $N F Y B$ and interfering $N F Y B(\mathbf{E}, \mathbf{H}, \mathbf{J})$, respectively. Significance: *, ** indicate $P<0.05$ and $P<0.01$, respectively. 


\section{Inducing of CCDC152 expression inhibits cell migration}

Furthermore, we tested whether $C C D C 152$ could inhibit the migratory ability of LMH cells by applying the wound healing and the transwell migration assays. Compared with the control cells transfected only with the empty vector, the wound healing ability (migratory ability) of cells was significantly decreased in LMH cells with overexpression of CCDC152 (Figure 8A). Additionally, compared with control, knockdown of CCDC152 in LMH cells resulted in a significant increase in the wound healing ability (Figure 8B). Compared to pc3.1-EGFP cells, $C C D C 152$ cells had a reduced ability to cross the transwell membrane, demonstrated by the weaker staining of the transwells in which they were seeded. Shown in the lower panel is the bar graph presentation of quantitative measurements of cell migration in control LMH cells (pc3.1-EGFP) and LMH cells over-expressing CCDC152 (pc3.1-CCDC152) (Figure 9A). Compared to si-NC cells, $C C D C 152$ cells had an increased ability to cross the transwell membrane, demonstrated by the stronger staining of the transwells in which they were seeded. Shown in the lower panel is the bar graph presentation

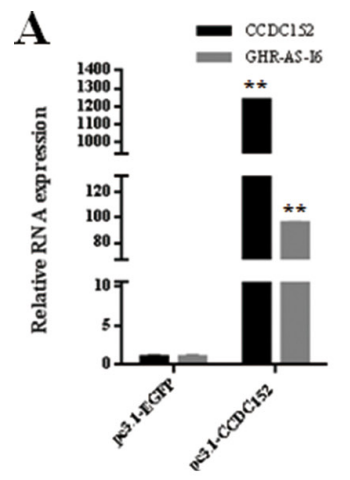

D

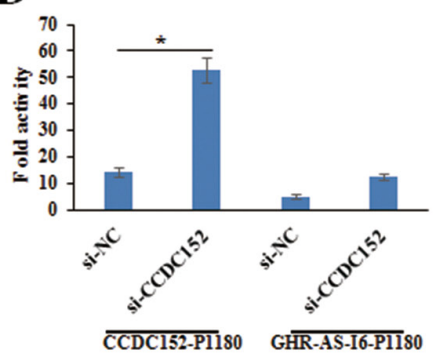

B

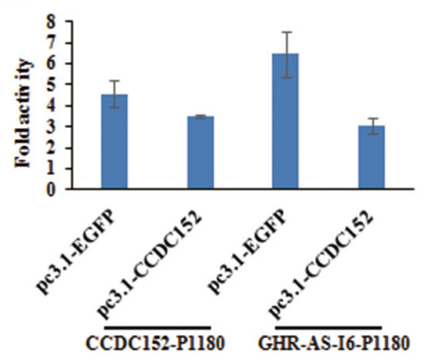

C

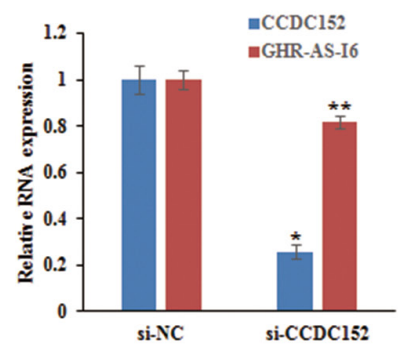

$\mathbf{E}$

F
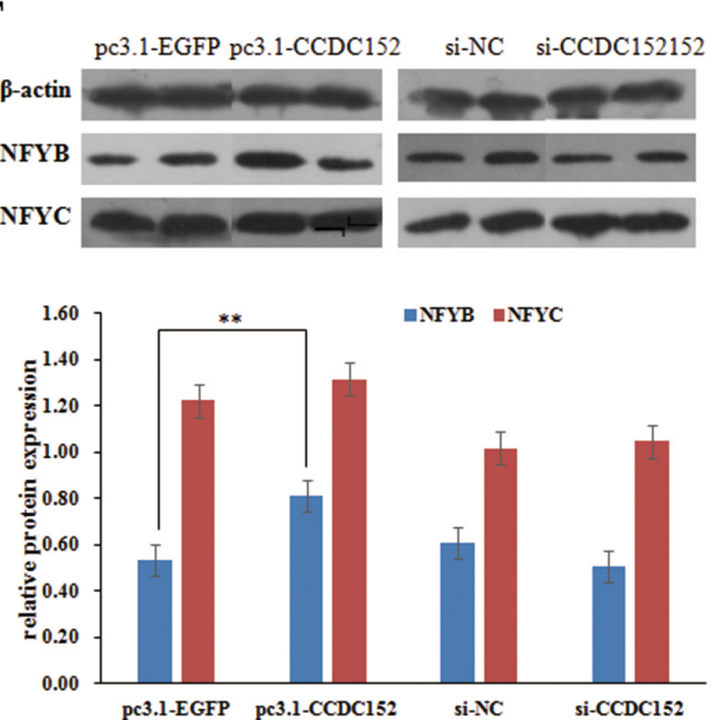

\section{G}
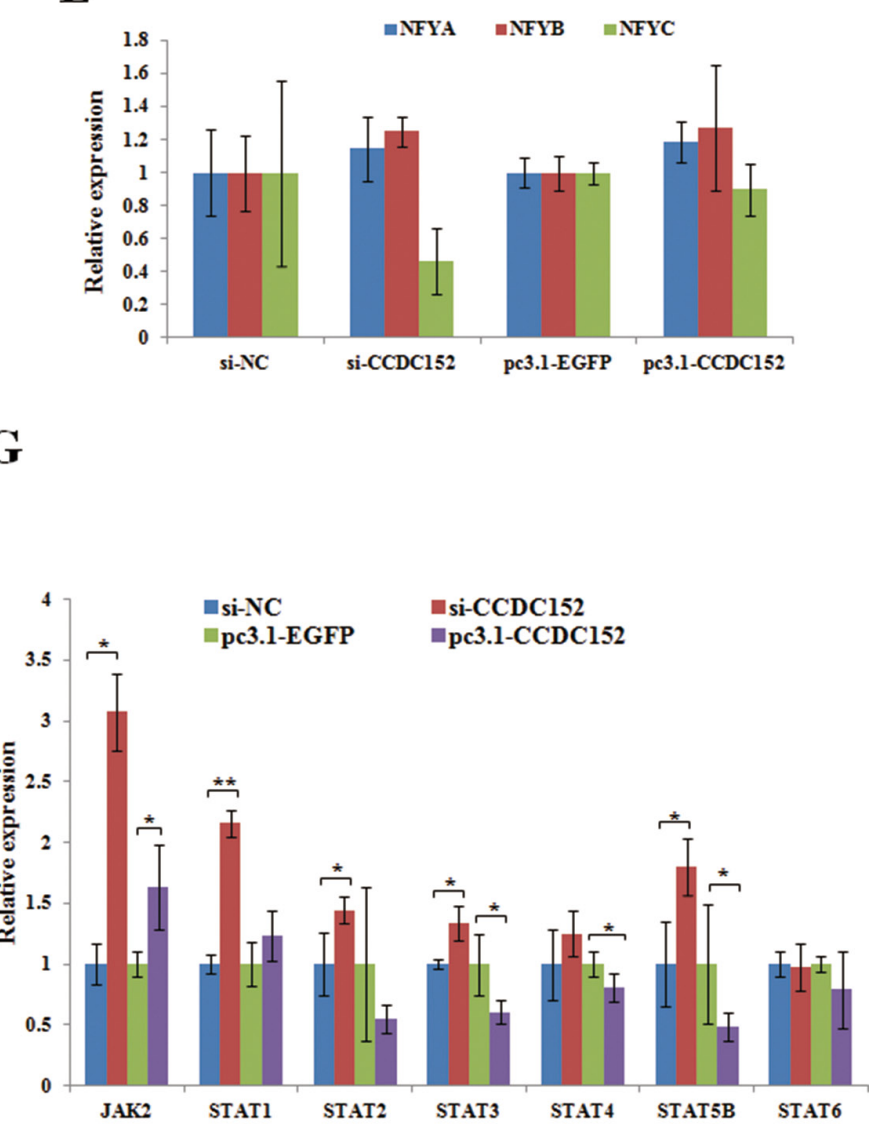

Figure 6: CCDC152 down-regulates the transcriptional activity of GHR-AS-I6-CCDC152 bidirectional promoter in LMH cells. The relative expression levels of GHR-AS-I6 (A, C), NFYA-C, JAK2 and STATs (E-G), and the bidirectional promoter activity (B, D) were changed by overexpressing and interfering CCDC152. Significance: *, ** indicate $P<0.05$ and $P<0.01$, respectively. 
of quantitative measurements of cell migration in control LMH cells (si-NC) and LMH cells knockdown CCDC152 (si-CCDC152) (Figure 9B).

\section{DISCUSSION}

Bidirectional promoters are a major source of gene activation-associated noncoding RNA $[9,11,36]$. Previous studies have demonstrated that bidirectional promoter is likely to contain $\mathrm{CpG}$ islands and many transcriptional factors in the core region, sometimes without the TATA box $[37,38]$. The present study clearly illustrates that GHR-AS-I6 and CCDC152 constitute a classical head-tohead pair that shares a prototypical bidirectional promoter for the first time. In addition, the intergenic distance between GHR-AS-I6 and CCDC152 is 504 bp or even less (102 bp) in some circumstances. Also, this region contains a TATA box and harbors a CCAAT box for NFYB, which

C
B

LMH

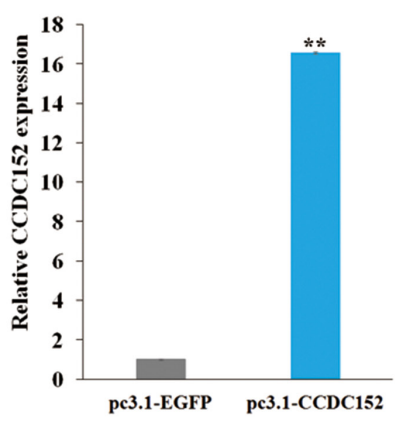

LMH

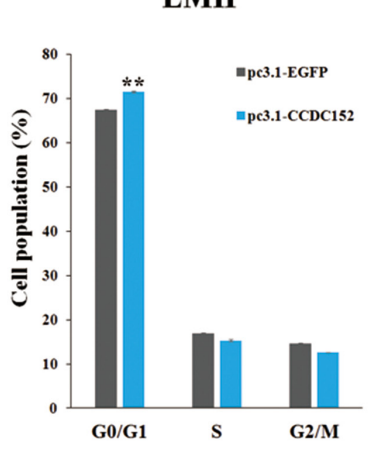

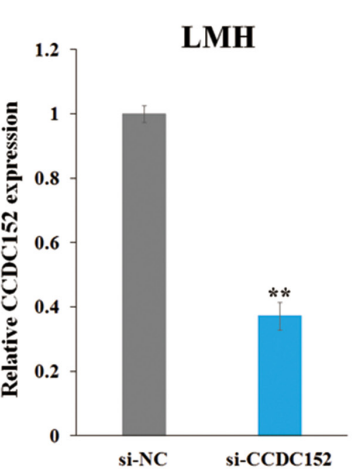

D

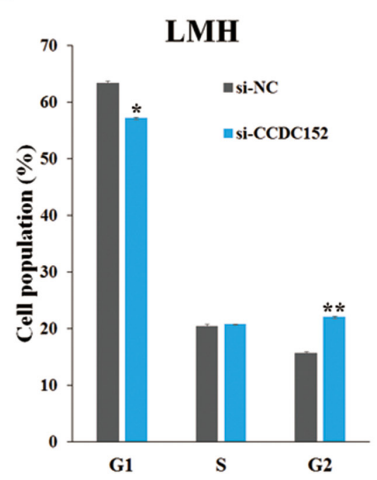

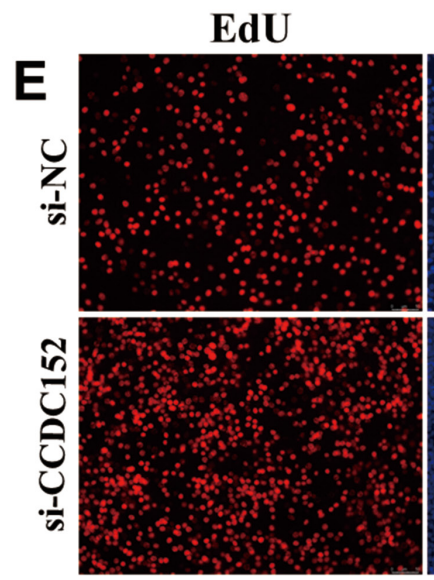

EdU

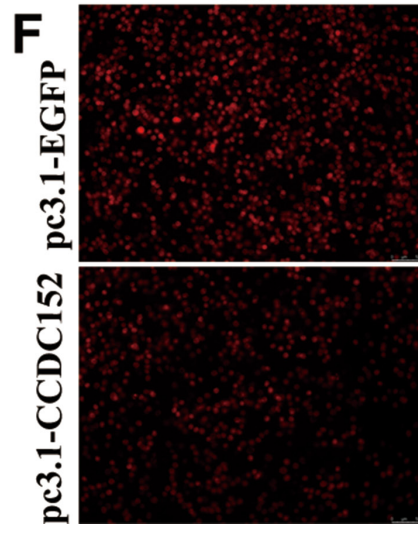

DAPI
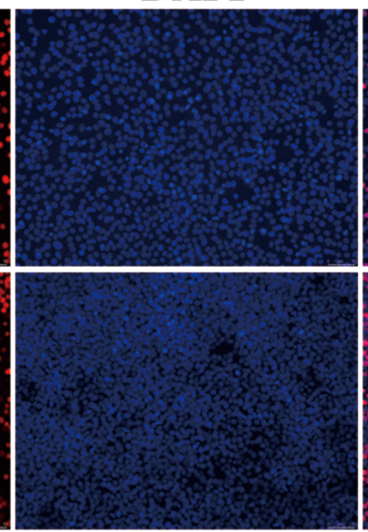

DAPI

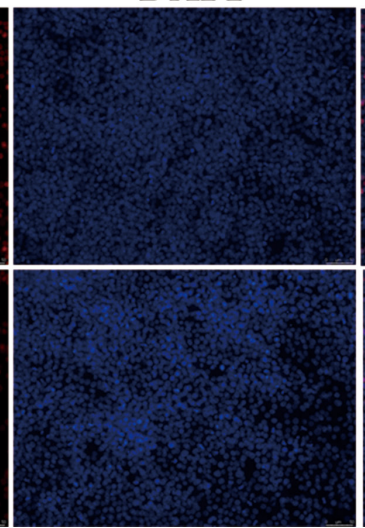

Overlay

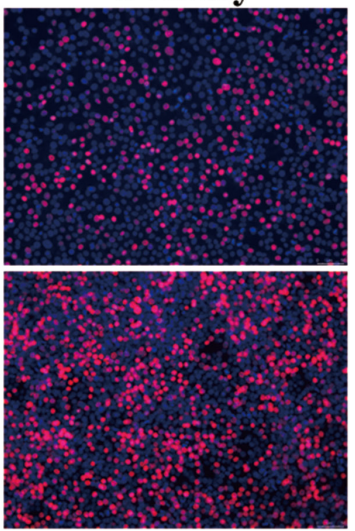

Overlay

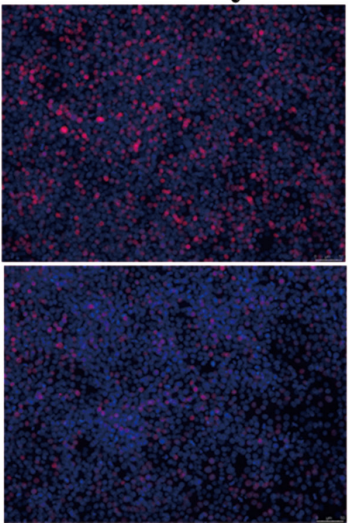

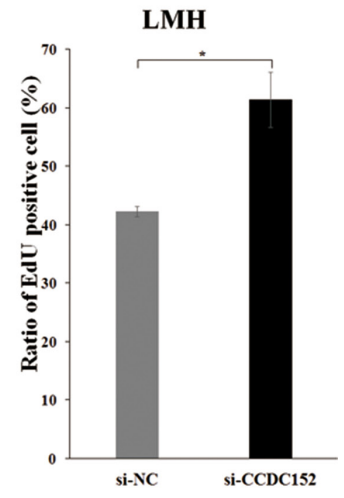

LMH

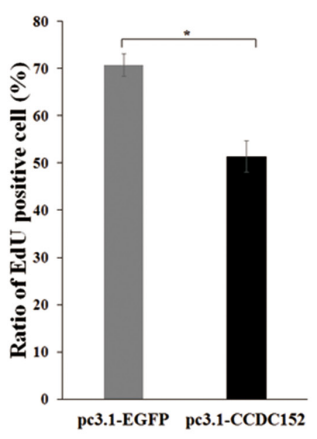

Figure 7: CCDC152 inhibits LMH cell proliferation. The relative expression of $C C D C 152$ after overexpressing $C C D C 152$ (A) and inhibiting CCDC152 (C). Cell cycle analysis of LMH cells $48 \mathrm{~h}$ after transfection using flow cytometry (B, D). EdU proliferation assays for the cells in $48 \mathrm{~h}$ after transfection (Scale bar, $10 \mu \mathrm{m})$ and the numbers of proliferative cells were also counted (E, F). Compared with the control, per Student's $t$-test, $* P<0.05$ and $* * P<0.01$. 
is frequently found in bidirectional promoters. Moreover, this region does not contain a $\mathrm{CpG}$ island (data not shown), which is sometimes presented in bidirectional promoters. The nuclear sequence-specific transcription factor NF-Y complex is a trimer that binds to the CCAAT box $[35,39]$ and participates in regulating proliferation by controlling the expression of genes required for cell cycle progression $[33,40]$ and transcriptional initiation of various genes $[13,34,41,42]$. In the present study, we demonstrate that the classic GHR-AS-I6-CCDC152 pair shares a prototypical bidirectional promoter that is regulated by NFYB/NFYC complex. Considering that only a few examples of such bidirectional promoter have been identified and mechanistically investigated to date, this study also represents a useful paradigm for analyzing the transcriptional regulation of bidirectional promoterdriven gene pairs.

It has been reported that $C C D C$ genes play important roles in the process of gene transcription $[14,29,43]$. In this study, the chicken CCDC152 can regulate the $G H R-A S-I 6-C C D C 152$ bidirectional promoter through JAK/STAT3/5 signaling pathway, which have been reported by other researchers to mediate genes' transcription [44, 45] and participate in cells proliferation, growth, differentiation, migration and invasion $[46,47]$. Previous studies have shown that $C C D C$ genes are relative to cellular progression, such as the cell cycle, proliferation and migration [28, 29, 48]. Notably, one of these genes, $C C D D 152$, was previously indicated to express in chicken liver and leg muscle tissues (Supplementary Figure 2). So we proposed that the chicken CCDC152 may play a pivotal role in cell proliferation and migration mediate JAK2/STAT signaling pathway. In this study, we investigated the suppressor function of CCDC152 in LMH cells. As expected, the overexpression of CCDC152 suppressed LMH cell development, including cell proliferation and migration by down-regulating JAK2, STAT3 and STAT5 expression. All these results show that CCDC152 plays pivotal role in inhibiting cell proliferation and migration by influencing JAK2/STAT signaling. However, further studies are needed to confirm whether the CCDC152 protein directly or indirectly activate/inactivate JAK2/STAT signaling to mediate cell proliferation, e.g. how the effect of CCDC152 overexpression blocking the STAT3/STAT5B pathway occurs on cells proliferation and whether CCDC152 regulates JAK2/STAT phosphorylation and their protein expressions.

In summary, as shown in Figure 10, NFYB combined with NFYC could target the CCAAT box of the bidirectional promoter to trigger both $G H R-A S-I 6$ and $C C D C 152$ transcriptions. A high level of CCDC152 protein can not only suppress the bidirectional promoter activity, but also inhibit cell proliferation and migration; conversely, a low level of CCDC152 protein can increase bidirectional promoter activity, as well as promote cellular proliferation and migration by mediating JAK2/STAT3/5 signaling pathway.
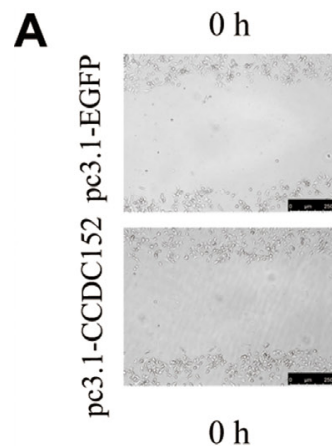

$6 \mathrm{~h}$

$12 \mathrm{~h}$
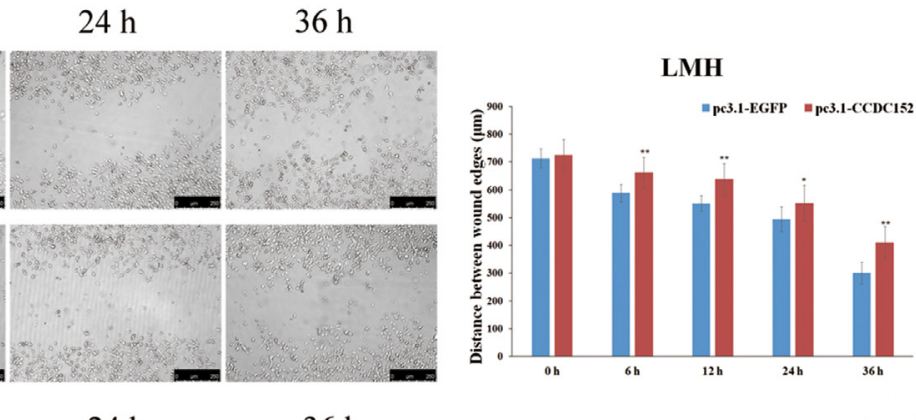

B
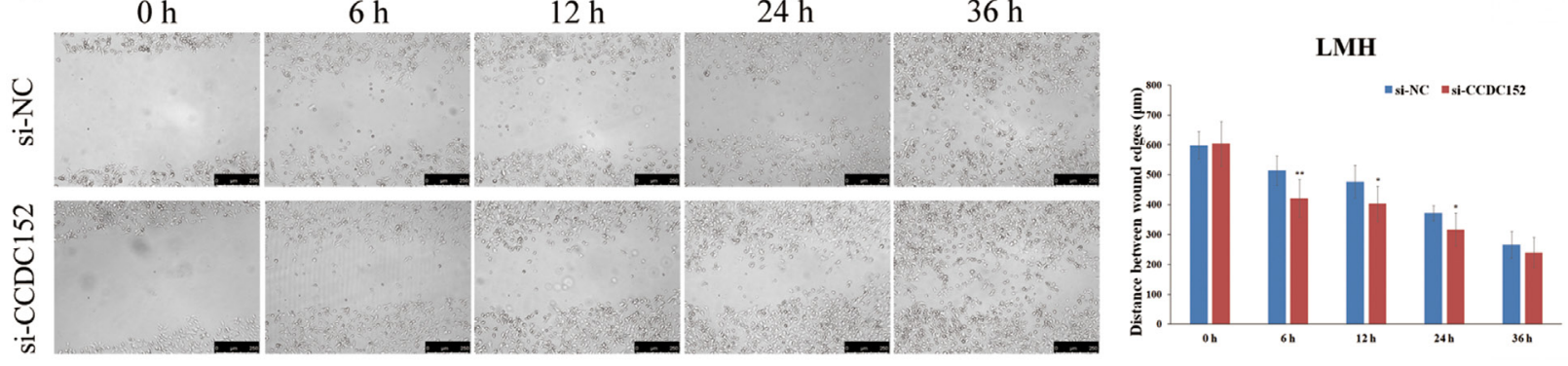

Figure 8: Wound healing assay of LMH cell migration. (A, B) Representative images of wound healing (cell migration) as described in the Methods, in LMH cells, with induced overexpression CCDC152 (pc3.1-CCDC152) or knockdown CCDC152 (si-CCDC152) and control cells transfected with the empty vector (pc3.1-EGFP) or si-NC. Bar graph presentation of the quantitative measurements of cell migration distance in cells overexpressing CCDC152 (pc3.1-CCDC152) or down-expression CCDC152 (si-CCDC152) and control cells (pc3.1-EGFP, si-NC). Columns represent the mean of at least four independent experiments and the little vertical bars at the top of the columns represent S.E.M. Compared with the control, per Student's $t$-test, $* P<0.05$ and $* * P<0.01$. 

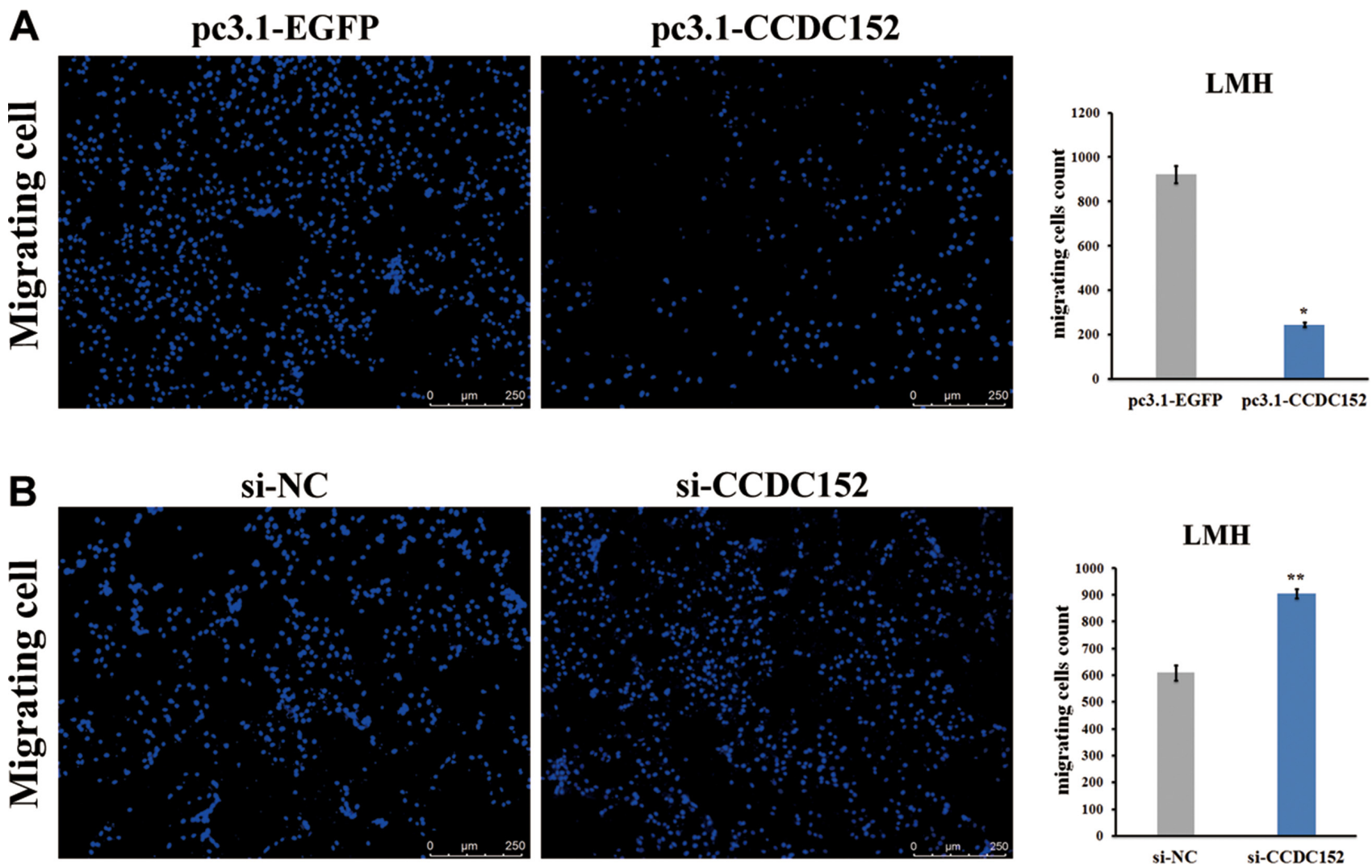

Figure 9: Transwell migration assays of LMH cells. (A, B) Shown in the left panel are representative microphotograph images of migrating LMH control cells (pc3.1-EGFP, si-NC) or cells transfected with stably introduced expression of CCDC152 (pc3.1-CCDC152) or interfering oligo of CCDC152 (si-CCDC152). Scale bar, $50 \mu \mathrm{m}$. Columns represent the mean of the counts of migrating cell numbers from at least 3 independent experiments, and the small vertical bars at the top of the columns represent S.E.M. Compared with the control, per Student's $t$-test in both panels A and $\mathrm{B}, * P<0.05$ and $* * P<0.01$.

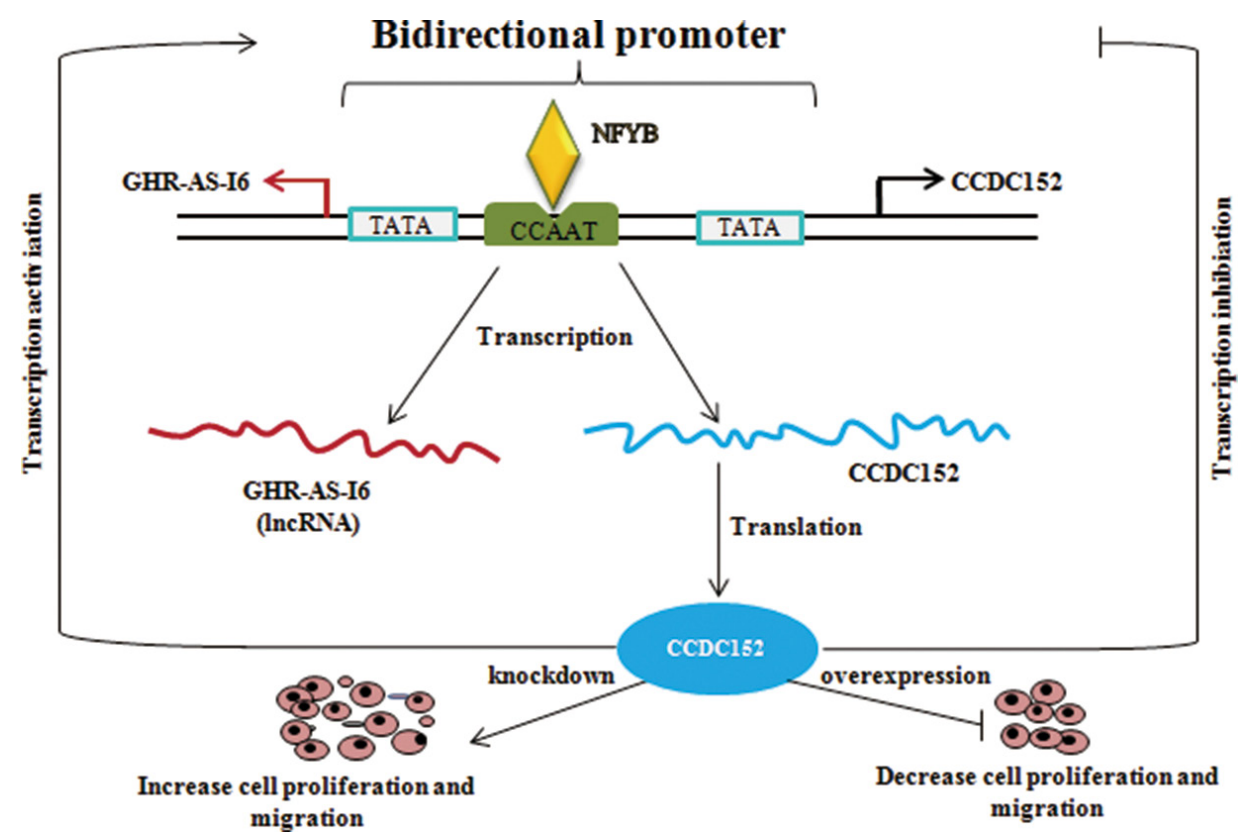

Figure 10: The NFYB controls chicken GHR-AS-I6-CCDC152 bidirectional promoter in LMH cells. The low level of $C C D C 152$ can positively regulate the bidirectional promoter to transcribe GHR-AS-I6 and CCDC152 (left), and in contrast, the high level of $C C D C 152$ will inhibit the activity of this bidirectional promoter (right). Therefore, $C C D C 152$ can balance the expression level of itself to regulate cell proliferation and migration. 


\section{MATERIALS AND METHODS}

\section{Ethics statement}

The Animal Care Committee of South China Agricultural University (Guangzhou, People's Republic of China) approved this study. The animals involved in this study were humanely sacrificed as necessary to ameliorate suffering.

\section{Computational analyses}

The chicken GHR and CCDC152 genes sequences were downloaded from NCBI database. The potential promoter region and transcriptional start sites of GHR-AS-I6$C C D C 152$ were predicted by online softwares PromoterScan (http://www-bimas.cit.nih.gov/molbio/proscan/) and Fruitfly (http://linux1.softberry.com/berry.phtml?topic=fgenesh\&gr oup $=$ programs\&subgroup $=$ gfind). The transcriptional start site of $C C D C 152$ was decided by $C C D C 152$ mRNA (NCBI: XM_015277374.1). The online tools Jaspar (http://jaspar. genereg.net/) and PROMO (http://alggen.lsi.upc.es/cgi-bin/ promo_v3/promo/promoinit.cgi?dirDB=TF_8.3) were used to predict the TATA box and transcriptional factor binding sites.

\section{Experimental animals}

White Recessive Rock (WRR) chicken at sevenweek-old was obtained from Experimental Poultry Farm of South China Agricultural University (Guangdong, China). Liver tissue samples were taken from the WRR and stored in liquid nitrogen before use.

\section{Extraction of genomic DNA}

Genomic DNA was extracted from the WRR chicken liver tissue samples following standard saturated phenol-chloroform extraction procedures. After extraction, DNA quantity was assessed using NanoDrop 2000 spectrophotometer (Thermo Scientific).

\section{Rapid amplification of cDNA 5' ends (5'-RACE)}

$5^{\prime}$-RACE was conducted using the PrimeScript ${ }^{\mathrm{TM}}$ II 1st Strand cDNA Synthesis Kit (Takara, Japan) and two steps of nested PCR. Primers were designed using Oligo7 so that a relatively large section of the non-coding region was amplified in addition to the $5^{\prime}$ untranslated region. Briefly, total RNAs were extracted from WRR chicken liver and leg muscle tissues using the Trizol reagent (Invitrogen, USA), and were reversely transcribed to obtain first-strand cDNA with the universal primer AUP1 onto the $5^{\prime}$ end following the PrimeScript ${ }^{\mathrm{TM}}$ II manual (Takara, Japan). There were a total of 6 tubes, each containing $20 \mu \mathrm{L}$ cDNA treated with RNase H. A total of $75 \mu \mathrm{L}$ of the reaction mixture was added to each tube, comprising $20 \mu \mathrm{L}$ reverse transcription product, $15 \mu \mathrm{L}$ $5 \times$ Hybrid RNA Degeneration Buffer, $1 \mu \mathrm{L}$ RNase H (60 $\mathrm{U} \cdot \mu \mathrm{L}-1)$, and $39 \mu \mathrm{L}$ DEPC water. Then, the solution was incubated at $30^{\circ} \mathrm{C}$ for $1 \mathrm{~h}$. Thereafter, the PCR product purification kit (Magen, China) was used to purify the RNase $\mathrm{H}$ treatment product. When the product was purified, the 2 tubes were combined into 1 tube through the cDNA of the enzyme solution, and $20 \mu \mathrm{L}$ elution buffer per tube was added. The purified cDNA $10 \mu \mathrm{L}, 5 \mathrm{x}$ TdT Buffer $10 \mu \mathrm{L}, 0.1 \%$ BSA $5 \mu \mathrm{L}, 100 \mathrm{mmol} \cdot \mathrm{L}-1 \mathrm{dCTP}$ $0.5 \mu \mathrm{L}$, TdT 1.5 L (ThermoFisher, USA), and double distilled water were added up to $50 \mu \mathrm{L}$, and the solution was incubated at $37^{\circ} \mathrm{C}$ for $5 \mathrm{~h}$ for TdT polyadenylation (ThermoFisher, USA). For each replicate, 2 tubes were used. After the end of treatment, the product was purified with PCR product purification kit (Magen, China), and the 2 tubes of products were combined into 1 tube for purification, washed, then eluted in with $30 \mu \mathrm{L}$ of elution buffer, and stored at $-30^{\circ} \mathrm{C}$.

The first round of PCR amplification was then examined using upstream universal outside primer AP1 and CCDC152 or GHR-AS-I6 gene-specific outside primer. The nested PCR based amplification was then performed using upstream universal inside primer AP2 and $C C D C 152$ or $G H R$ - $A S$-I6 gene-specific inside primers (Supplementary Table 1). The PCR procedure was as follows: $95^{\circ} \mathrm{C}$ for $3 \mathrm{~min}$ for degeneration; $95^{\circ} \mathrm{C}$ for 40 s, $72^{\circ} \mathrm{C}$ for $3 \mathrm{~min}$ for two cycles; $95^{\circ} \mathrm{C}$ for $40 \mathrm{~s}, 70^{\circ} \mathrm{C}$ for $3 \mathrm{~min}$ for two cycles; $95^{\circ} \mathrm{C}$ for $40 \mathrm{~s}, 68^{\circ} \mathrm{C}$ for $3 \mathrm{~min}$ for two cycles; and $95^{\circ} \mathrm{C}$ for $40 \mathrm{~s}, 66^{\circ} \mathrm{C}$ for $50 \mathrm{~s}, 72^{\circ} \mathrm{C}$ for $3 \mathrm{~min}$, for 30 cycles. PCR products were gel-purified using a $1.5 \%$ gel and PCR product purification kit (Magen, China), cloned into pMD18T Vector (Takara, Japan), and sequenced by Shanghai Sangon Biotech (Guangzhou, China). The RACE sequences were subsequently compared with the genomic sequences of CCDC152 and GHR-AS-I6 to confirm gene identity, exon usage, and location of the transcription start sites.

\section{Cell culture}

The chicken LMH cells line was donated by Harbin Veterinary Research Institute Chinese Academy of Agricultural Science (Heilongjiang, China). We cultured them in high-glucose Dulbecco's modified Eagle's medium (Gibco, Grand Island, NY, USA) with 10\% heat-inactivated fetal bovine serum (Invitrogen, USA), penicillin (100 IU $\cdot \mathrm{mL}-1)$, and streptomycin $(100 \mu \mathrm{g}$. mL-1) (Invitrogen, Carlsbad, CA, USA). All cells were maintained at $37^{\circ} \mathrm{C}$ in $5 \% \mathrm{CO} 2$.

\section{Luciferase reporter constructs and reporter assays}

The qualitative analyses of the bidirectional promoter GFP luciferase reporter pEGFP-CCDC152-P1180 and pEGFP-GHR-AS-I6-P1180 were generated by cloning the corresponding intergenic region between GHR 3' 
flanking region and CCDC152 into the pEGFP-N1 vector to substitute its $\mathrm{CMV}$ region, and pLinker-EGFP was the result of deletion of the CMV region of pEGFP-N1 using $\Omega-P C R$ as reported elsewhere [49]. The primer sequences and the restriction enzymes used are listed in Supplementary Table S1. LMH cells were inoculated into 24 wells, approximately $2.5 \times 10^{5}$ cells per well. According to the manufacturer's instructions for Lipofectamine3000, pEGFP-CCDC152-P1180 and pEGFP-GHR-AS-I6-P1180 were used for transfection of LMH cells, and a positive (pEGFP-N1 transfected cells) and negative control group (pLinker-EGFP transfected cells) were created. After 48 $\mathrm{h}$ of transfection, fluorescence was observed under Nikon Eclipse microscopy (Nikon, Tokyo, Japan).

The luciferase reporters CCDC152-P1180, CCDC152-P874, CCDC152-P504, CCDC152-P317, CCDC152-P102, GHR-AS-I6-P1180, GHR-AS-I6-P874, GHR-AS-I6-P504, GHR-AS-I6-P317 and GHR-AS-I6-102 were generated by cloning the corresponding intergenic region between $G H R$ 3' flanking region and CCDC152 into the pGL3-basic vector using PCR or deletion $\Omega$-PCR [49]. The primer sequences and the restriction enzymes used are also listed in Supplementary Table 1. For luciferase reporter assays, cells were seeded in triplicate into 24-well plates and co-transfected with the indicated reporter plasmid, pRL-TK vector (Promega) encoding Renilla luciferase and the pcDNA3.1 empty vector or a transcription factor expression vector using Lipofectamine 3000 (Invitrogen, USA). Then $48 \mathrm{~h}$ after transfection, cells were lysed with passive lysis buffer, and luciferase activity was measured using the Dual-Luciferase Assay System (Promega) according to the manufacturer's protocols.

\section{Site mutation constructs and transient transfection assays}

Various progressive deletion mutants (M1-M8, M1'-M8') were further constructed using either a DNA blunting kit (Takara, Japan) with restriction enzyme digestion and ligation, or the Site-Directed Mutagenesis Kit (TOYOBO, Japan) with reverse PCR amplification and ligation, according to the manufacturers' instructions. Constructs with point mutation(s) at putative transcription factor binding sites were generated using $\Omega-P C R$ [49]. The primer sequences and the restriction enzymes used are listed in Supplementary Table 1. All constructs were validated by direct sequencing, and the transient transfection assays were conducted as above.

\section{Overexpression and siRNA transfection}

The overexpression constructs pc3.1-CCDC152 and pc3.1-NFYB were the results of their CDS-sequences inserted into a pcDNA-3.1 vector. All siRNAs were chemically synthesized by Shanghai GenePharma (Shanghai, China). The sequences of the siRNAs used are listed in Table 1. The perfect concentration of pc3.1-
CCDC152, pc3.1-NFYB (Supplementary Figure 3) and siRNAs (Supplementary Figure 4) were transfected into the indicated cells using Lipofectamine 3000 (Invitrogen, USA) according to the manufacturer's instructions. Cells were then collected and subjected to analysis $48 \mathrm{~h}$ after transfection. The experiments were repeated at least in triplicate.

\section{RNA isolation and qRT-PCR}

Total RNA isolation was conducted with RNA Isolation Tissue Kit (BIOMEGA), and reverse transcription was performed with PrimerScript ${ }^{\mathrm{TM}}$ II Kit (TaKaRa, Japan) to prepare cDNA. The resulting cDNA was used in qRTPCR reactions with $i T_{a q}{ }^{\mathrm{TM}}$ universal SYBR ${ }^{\circledR}$ Green (BioRad) on a MasterCycle Realplex2 SYSTEM (Eppendorf) and analyzed as described. The sequences of the primers used are provided in Supplementary Table 1.

\section{Chromatin immunoprecipitation assay}

Chromatin immunoprecipitation (ChIP) assays were performed according to the ChIP Assay Kit (Beyotime, Shanghai, China). Briefly, LMH cells were treated with $37 \%$ formaldehyde and incubated for $10 \mathrm{~min}$ to generate DNA-protein cross-links. Cell lysates were then sonicated to generate chromatin fragments of 200-500 bp and immunoprecipitated with antibodies against anti-NFYB and anti-NFYC (LSBio, USA) or IgG antibody (Beyotime, Shanghai, China) as negative control (NC). The antibodybound complex was precipitated by Protein $\mathrm{A}+\mathrm{G}$ Agarose beads. The DNA fragments in the immunoprecipitated complex were released by reversing the cross-linking at $65^{\circ} \mathrm{C}$ for 4 hour and purified DNA was analyzed by PCR and qRT-PCR with iTaq ${ }^{\mathrm{TM}}$ universal SYBR ${ }^{\circledR}$ Green (Bio$\mathrm{Rad}$ ). The $\Delta \mathrm{Ct}$ was calculated as $\Delta \mathrm{Ct}$ (normalized ChIP) $=[\mathrm{Ct}(\mathrm{ChIP})-\mathrm{Ct}$ (Input) $]$. The $\%$ input was shown as 2 $[-\Delta \mathrm{Ct}$ (normalized ChIP)]. The primers specific for the $\mathrm{P} 102$ region of the bidirectional promoter containing CCAAT box were shown in Supplementary Table 1.

\section{Western blot analysis}

For Western blotting, $30 \mathrm{mg}$ of fresh frozen treated cells were lysed in ROPA lysis buffer (Cwbiotech, China) containing 1\% Protease Inhibitor Cocktail (Cwbiotech, China). An equal amount of protein, approximately $30 \mu \mathrm{g}$, was separated by sodium dodecyl sulfate polyacrylamide gel electrophoresis (SDS-PAGE) and transferred onto the poly vinylidene flouride (PVDF) membrane. After blocking with 5\% skimmed milk, the PVDF membrane was incubated with anti-CCDC152 (Santa, USA), anti-NFYB and anti-NFYC (LSBio, USA) antibodies, respectively. After washing three times with Tris-Buffered Saline and Tween 20, the membrane was incubated with horseradish peroxidase-linked secondary anti-goat or antirabbit IgG antibody (Santa, USA) at room temperature for $1 \mathrm{~h}$, followed by visualization using an ECL detection 


\begin{tabular}{cl}
\hline Name & \multicolumn{1}{c}{ Sequence (5'-3') } \\
\hline si-NC & UUCUCCGAACGUGUCACGUTT \\
& ACGUGACACGUUCGGAGAATT \\
si-CCDC152 & GAAACACCAUAAGAGACUUTT \\
& AAGUCUCUUAUGGUGUUUCTT \\
si-NFYB & CCGAUUGCAAACGUGGCAATT \\
& UUGCCSCGUUUGCAAUCGGTT \\
\hline
\end{tabular}

kit (Millipore, Billerica, MA). Anti- $\beta$-actin antibody was purchased from Abcam and used as loading controls. An ImageMaster DVS system was used to calculate the relative mean gray values (A) of the target product and $\beta$-actin. Expression index (I) of the target produce was calculated using the formula of $\mathrm{I}=\mathrm{A}$ produce/A $\beta$-actin.

\section{Cell proliferation assay}

Cell cycle analysis: Cells transfected with pc3.1CCDC152 and si-CCDC152, and control cells were harvested $72 \mathrm{~h}$ after culture, washed with cold phosphate buffered saline (PBS), and fixed in $1 \mathrm{~mL}$ of cold $70 \%$ ethanol. After overnight incubation at $-20^{\circ} \mathrm{C}$ in ethanol, cells were washed in PBS and suspended in $500 \mathrm{~mL}$ propidine iodide (PI) for $30 \mathrm{~min}$ before flow cytometry. Populations in G1, S and G2 phases were measured by flow cytometry (Beckman, CA), and the data were analyzed using the Multicycle-DNA Cell Cycle Analysis Software. The measurements were performed four times.

DNA synthesis in proliferating cells was determined by EdU assay, using Cell-Light ${ }^{\mathrm{TM}}$ EdU Appolo567 In Vitro Kit (Ribobio, China) following manufacturer's instructions. Treated cells were observed using fluorescence microscope (Leica, Germany). Experiments were repeated at least three times in duplicates.

\section{Wound-healing assay and transwell migration assay}

A wound healing assay was carried out to detect the migration of cells, and the three kinds of transfectant cells were cultured in 24-well plates until confluent. The cell layer was wounded using a sterile tip. After incubation for 0 to $48 \mathrm{~h}$, cells were photographed under an inverted microscope (Leica, Germany). Experiments were carried out four times. The distance between the two edges of the scratch (wound width) was measured at 8 sites $(100 \times$ magnification) in each image. The cell migration distance was measured using Image J by measuring the wound width at $0 \mathrm{~h}$ and at each time point, and then dividing by two.

For migration assay, $200 \mu \mathrm{L}$ of the pc3.1-CCDC152, si-CCDC152 and NC cells (transfected for $12 \mathrm{~h}$ ) in serum-free DMEM were seeded on upper migration chambers (24-well plats, 8- $\mu \mathrm{m}$ pore size. Corning Incorporated Costar, USA) at a density of $2 \times 10^{5}$ cells/ well, and incubated at $37{ }^{\circ} \mathrm{C}$ and $5 \% \mathrm{CO}_{2}$. A volume of
$700 \mu \mathrm{L}$ of DMEM containing $10 \%$ fetal bovine serum was added in the lower chamber. After incubation for $24 \mathrm{~h}$, the migrating cells in the upper migration chambers were fixed with $800 \mu \mathrm{L} \mathrm{4 \%}$ paraformaldehyde at room temperature for $30 \mathrm{~min}$, and then stained with $800 \mu \mathrm{L}$ $0.1 \%$ DAPI (Ribobio, China) at room temperature for $30 \mathrm{~min}$. The unpenetrated cells on the upper chamber were gently scraped from the surface with cotton swabs. Six visual fields $(100 \times$ magnification $)$ were selected for each chamber and photographed under an inverted microscope (Leica, Germany) and the number of penetrated cells in these six fields was counted by ImageJ software. The mean value of each group was recorded.

\section{Statistical analyses}

The relative expression level of the target gene was calculated with the $2^{-\Delta \Delta \mathrm{Ct}}$ method and error bars represent the SEM from at least three repeats. To know the significance of the observed differences, $P$-values were assessed using two-tailed unpaired, Student's $t$-test with $P$-values $<0.05$ or less considered to be statistically significant.

\section{Abbreviations}

CCDC152, coiled-coil domain-containing protein 152; GHR, growth hormone receptor; GHR-AS-I6, GHR antisense transcript intron 6; LMH: chicken hepatocellular carcinoma cell line; qRT-PCR: quantitative real-time polymerase chain reaction; ChIP: chromatin immunoprecipitation; NFYB/NFYC, nuclear transcription factor Y subunit beta/gamma; JAK, Janus kinase; STAT, signal transducer and activator of transcription.

\section{Author contributions}

The manuscript was written through contributions of all authors. Shudai Lin substantially contributed to design, performed experiment and data analysis, and drafted the article. Wei Luo and Mingya Jiang helped to perform experiment and data analysis. Wen Luo provided many precious opinions in statistical analyses. Bahareldin Ali Abdalla reviewed the manuscript. Qinghua Nie, Li Zhang and Xiquan Zhang designed this study with Shudai Lin, and revised it critically for important intellectual content. Xiquan 
Zhang finally gave approval of the article to be published. All authors read and approved the final manuscript.

\section{ACKNOWLEDGMENTS AND FUNDING}

We would like to thank Prof. Yunfeng Wang and Yan Zhao (Harbin Veterinary Research Institute, Chinese Academy of Agricultural Science, Heilongjiang, China) for donating us LMH cells. This work was supported by the High Technology Research and Development Program of China (2013AA102501), the National Natural Science Foundation (31301958, 31672412), and the China Agriculture Research System (CARS-41-G03).

\section{CONFLICTS OF INTEREST}

The authors declare no conflicts of interest.

\section{REFERENCES}

1. Blattner FR, Plunkett G, Bloch CA, Perna NT, Burland V, Riley M, Collado-Vides J, Glasner JD, Rode CK, Mayhew GF, Gregor J, Davis NW, Kirkpatrick HA, et al. The complete genome sequence of Escherichia coli K-12. Science. 1997; 277:1453-62.

2. Venter JC, Smith HO, Adams MD. The Sequence of the Human Genome. Clin Chem. 2015; 61:1207-8.

3. Rinaldi C, Haddad F, Bodell PW, Qin AX, Jiang W, Baldwin KM. Intergenic bidirectional promoter and cooperative regulation of the IIx and IIb MHC genes in fast skeletal muscle. Am J Physiol Regul Integr Comp Physiol. 2008; 295:R208-18.

4. Orekhova AS, Rubtsov PM. Bidirectional promoters in the transcription of mammalian genomes. Biochemistry (Mosc). 2013; 78:335-41.

5. Bagchi DN, Iyer VR. The Determinants of Directionality in Transcriptional Initiation. Trends Genet. 2016; 32:322-33.

6. Adachi N, Lieber MR. Bidirectional gene organization: a common architectural feature of the human genome. Cell. 2002; 109:807-9.

7. Trinklein ND, Aldred SF, Hartman SJ, Schroeder DI, Otillar RP, Myers RM. An abundance of bidirectional promoters in the human genome. Genome Res. 2004; 14:62-66.

8. Voth H, Oberthuer A, Simon T, Kahlert Y, Berthold F, Fischer M. Co-regulated expression of HAND2 and DEIN by a bidirectional promoter with asymmetrical activity in neuroblastoma. BMC Mol Biol. 2009; 10:28.

9. Uesaka M, Nishimura O, Go Y, Nakashima K, Agata K, Imamura T. Bidirectional promoters are the major source of gene activation-associated non-coding RNAs in mammals. BMC Genomics. 2014; 15:35.

10. Hamazaki $N$, Uesaka $M$, Nakashima $K$, Agata $K$, Imamura $\mathrm{T}$. Gene activation-associated long noncoding RNAs function in mouse preimplantation development. Development. 2015; 142:910-20.
11. Yamamoto $\mathrm{N}$, Agata $\mathrm{K}$, Nakashima $\mathrm{K}$, Imamura $\mathrm{T}$. Bidirectional promoters link cAMP signaling with irreversible differentiation through promoter-associated non-coding RNA (pancRNA) expression in PC12 cells. Nucleic Acids Res. 2016; 44:5105-22.

12. Ji Y, Xie M, Lan H, Zhang Y, Long Y, Weng H, Li D, Cai W, Zhu H, Niu Y, Yang Z, Zhang C, Song F, et al. PRR11 is a novel gene implicated in cell cycle progression and lung cancer. Int J Biochem Cell Biol. 2013; 45:645-56.

13. Wang Y, Zhang Y, Zhang C, Weng H, Li Y, Cai W, Xie M, Long Y, Ai Q, Liu Z, Du G, Wang S, Niu Y, et al. The gene pair PRR11 and SKA2 shares a NF-Y-regulated bidirectional promoter and contributes to lung cancer development. Biochim Biophys Acta. 2015; 1849:1133-44.

14. Li YY, Yu H, Guo ZM, Guo TQ, Tu K, Li YX. Systematic analysis of head-to-head gene organization: evolutionary conservation and potential biological relevance. PLoS Comput Biol. 2006; 2:e74.

15. Yang MQ, Koehly LM, Elnitski LL. Comprehensive annotation of bidirectional promoters identifies co-regulation among breast and ovarian cancer genes. PLoS Comput Biol. 2007; 3:e72.

16. Gavalas A, Dixon JE, Brayton KA, Zalkin H. Coexpression of two closely linked avian genes for purine nucleotide synthesis from a bidirectional promoter. Mol Cell Biol. 1993; 13:4784-92.

17. Gavalas A, Zalkin H. Analysis of the chicken GPAT/AIRC bidirectional promoter for de novo purine nucleotide synthesis. J Biol Chem. 1995; 270:2403-10.

18. Tan M, Wei C, Price CM. The telomeric protein Rap1 is conserved in vertebrates and is expressed from a bidirectional promoter positioned between the Rap1 and KARS genes. Gene. 2003; 323:1-10.

19. Zhang L, Lin S, An L, Ma J, Qiu F, Jia R, Nie Q, Zhang D, Luo Q, Li T, Wang Z, Zhang X. Chicken GHR natural antisense transcript regulates GHR mRNA in LMH cells. Oncotarget. 2016; 7:73607-17. https://doi.org/10.18632/oncotarget.12437.

20. Tamaki H, Sanda M, Katsumata O, Hara Y, Fukaya M, Sakagami H. Pilt is a coiled-coil domain-containing protein that localizes at the trans-Golgi complex and regulates its structure. FEBS Lett. 2012; 586:3064-70.

21. Orgil O, Mor H, Matityahu A, Onn I. Identification of a region in the coiled-coil domain of $\mathrm{Smc} 3$ that is essential for cohesin activity. Nucleic Acids Res. 2016; 44:6309-17.

22. Burkhard P, Stetefeld J, Strelkov SV. Coiled coils: a highly versatile protein folding motif. Trends Cell Biol. 2001; 11:82-88.

23. Morra F, Luise C, Visconti R, Staibano S, Merolla F, Ilardi G, Guggino G, Paladino S, Sarnataro D, Franco R, Monaco R, Zitomarino F, Pacelli R, et al. New therapeutic perspectives in CCDC6 deficient lung cancer cells. Int $\mathrm{J}$ Cancer. 2015; 136:2146-57.

24. Jiang GY, Zhang XP, Zhang Y, Xu HT, Wang L, Li QC, Wang EH. Coiled-coil domain-containing protein 8 inhibits the invasiveness and migration of non-small cell lung cancer cells. Hum Pathol. 2016; 56:64-73. 
25. Chen M, Ni J, Chang HC, Lin CY, Muyan M, Yeh S. CCDC62/ERAP75 functions as a coactivator to enhance estrogen receptor beta-mediated transactivation and target gene expression in prostate cancer cells. Carcinogenesis. 2009; 30:841-50.

26. Yin DT, Xu J, Lei M, Li H, Wang Y, Liu Z, Zhou Y, Xing M. Characterization of the novel tumor-suppressor gene CCDC67 in papillary thyroid carcinoma. Oncotarget. 2016; 7:5830-41. https://doi.org/10.18632/oncotarget.6709.

27. Radulovich N, Leung L, Ibrahimov E, Navab R, Sakashita S, Zhu CQ, Kaufman E, Lockwood WW, Thu KL, Fedyshyn Y, Moffat J, Lam WL, Tsao MS. Coiled-coil domain containing 68 (CCDC68) demonstrates a tumorsuppressive role in pancreatic ductal adenocarcinoma. Oncogene. 2015; 34:4238-47.

28. Tsolakis AV, Grimelius L, Islam MS. Expression of the coiled coil domain containing protein 116 in the pancreatic islets and endocrine pancreatic tumors. Islets. 2012; 4:349-353.

29. Gong Y, Qiu W, Ning X, Yang X, Liu L, Wang Z, Lin J, Li X, Guo Y. CCDC34 is up-regulated in bladder cancer and regulates bladder cancer cell proliferation, apoptosis and migration. Oncotarget. 2015; 6:25856-67. https://doi. org/10.18632/oncotarget.4624.

30. Pasek RC, Malarkey E, Berbari NF, Sharma N, Kesterson RA, Tres LL, Kierszenbaum AL, Yoder BK. Coiled-coil domain containing 42 (Ccdc42) is necessary for proper sperm development and male fertility in the mouse. Dev Biol. 2016; 412:208-18.

31. Mu H, Ohta K, Kuriyama S, Shimada N, Tanihara H, Yasuda K, Tanaka H. Equarin, a novel soluble molecule expressed with polarity at chick embryonic lens equator, is involved in eye formation. Mech Dev. 2003; 120:143-55.

32. Della NI, Carra S, Brusegan C, Critelli R, Frassine A, De Lorenzo C, Giordano A, Bellipanni G, Villa E, Cotelli F, Pistocchi A, Schepis F. The Coiled-Coil Domain Containing $80(\operatorname{ccdc} 80)$ gene regulates gadd $45 \beta 2$ expression in the developing somites of zebrafish as a new player of the hedgehog pathway. J Cell Physiol. 2015; 230:821-30.

33. Benatti P, Dolfini D, Viganò A, Ravo M, Weisz A, Imbriano C. Specific inhibition of NF-Y subunits triggers different cell proliferation defects. Nucleic Acids Res. 2011; 39:5356-68.

34. Dolfini D, Gatta R, Mantovani R. NF-Y and the transcriptional activation of CCAAT promoters. Crit Rev Biochem Mol Biol. 2012; 47:29-49.

35. Imbriano C, Gurtner A, Cocchiarella F, Di Agostino S, Basile V, Gostissa M, Dobbelstein M, Del Sal G, Piaggio G, Mantovani R. Direct p53 transcriptional repression: in vivo analysis of CCAAT-containing G2/M promoters. Mol Cell Biol. 2005; 25:3737-51.

36. Ravasi T, Suzuki H, Pang KC, Katayama S, Furuno M, Okunishi R, Fukuda S, Ru K, Frith MC, Gongora MM, Grimmond SM, Hume DA, Hayashizaki Y, et al, Experimental validation of the regulated expression of large numbers of non-coding RNAs from the mouse genome. Genome Res. 2006; 16:11-19.
37. Liu X, Zhou X, Li Y, Tian J, Zhang Q, Li S, Wang L, Zhao J, Chen R, Fan Y. Identification and functional characterization of bidirectional gene pairs and their intergenic regions in maize. BMC Genomics. 2014; 15:338.

38. Lin S, Zhang L, Luo W, Zhang X. Characteristics of Antisense Transcript Promoters and the Regulation of Their Activity. Int J Mol Sci. 2015; 17:17.

39. Elkon R, Linhart C, Sharan R, Shamir R, Shiloh Y. Genomewide in silico identification of transcriptional regulators controlling the cell cycle in human cells. Genome Res. 2003; 13: 773-80.

40. Nardini M, Gnesutta N, Donati G, Gatta R, Forni C, Fossati A, Vonrhein C, Moras D, Romier C, Bolognesi M, Mantovani R. Sequence-specific transcription factor NF-Y displays histone-like DNA binding and H2B-like ubiquitination. Cell. 2013; 152:132-43.

41. Romier C, Cocchiarella F, Mantovani R, Moras D. The NF-YB/NF-YC structure gives insight into DNA binding and transcription regulation by CCAAT factor NF-Y. J Biol Chem. 2003; 278:1336-45.

42. Nakamura S, Nagata Y, Tan L, Takemura T, Shibata K, Fujie M, Fujisawa S, Tanaka Y, Toda M, Makita R, Tsunekawa K, Yamada M, Yamaoka M, et al. Transcriptional repression of Cdc25B by IER5 inhibits the proliferation of leukemic progenitor cells through NF-YB and p300 in acute myeloid leukemia. PLoS One. 2011; 6:e28011.

43. McFarlane AA, Orriss GL, Stetefeld J. The use of coiledcoil proteins in drug delivery systems. Eur J Pharmacol. 2009; 625:101-7.

44. Wang H, Chen X, He T, Zhou Y, Luo H. Evidence for tissue-specific Jak/STAT target genes in Drosophila optic lobe development. Genetics. 2013; 195:1291-306.

45. Lui AJ, Geanes ES, Ogony J, Behbod F, Marquess J, Valdez K, Jewell W, Tawfik O, Lewis-Wambi J. IFITM1 suppression blocks proliferation and invasion of aromatase inhibitor-resistant breast cancer in vivo by JAK/STAT-mediated induction of p21. Cancer Lett. 2017; 399:29-43.

46. Ouyang J, Pan X, Lin H, Hu Z, Xiao P, Hu H. GKN2 increases apoptosis, reduces the proliferation and invasion ability of gastric cancer cells through down-regulating the JAK/STAT signaling pathway. Am J Transl Res. 2017; 9:803-11.

47. Komar HM, Serpa G, Kerscher C, Schwoegl E, Mace TA, Jin M, Yang MC, Chen CS, Bloomston M, Ostrowski MC, Hart PA, Conwell DL, Lesinski GB. Inhibition of Jak/STAT signaling reduces the activation of pancreatic stellate cells in vitro and limits caerulein-induced chronic pancreatitis in vivo. Sci Rep. 2017; 7:1787.

48. Ha GH, Kim JL, Breuer EK. Transforming acidic coiledcoil proteins (TACCs) in human cancer. Cancer Lett. 2013; 336:24-33.

49. Chen L, Wang F, Wang X, Liu YG. Robust one-tube $\Omega$-PCR strategy accelerates precise sequence modification of plasmids for functional genomics. Plant Cell Physiol. 2013; 54:634-42. 